\title{
O Arquivo Histórico do Museu Imperial e as pesquisas sobre o século XIX
}

\author{
Researching the nineteenth \\ century: the Museu Imperial's \\ bistorical archives
}

${ }^{1}$ Catálogo manuscrito relativo à escravidão, Petrópolis, Fundação Pró-Memória, 1990.
S ão poucos ainda os cientistas sociais que conhecem o acervo $\checkmark$ arquivístico do Museu Imperial em Petrópolis, instituição pertencente ao Instituto do Patrimônio Histórico e Artístico Nacional (Iphan) do Ministério da Cultura. Não vamos descrever o conteúdo de cada acervo existente neste arquivo histórico — trabalho próprio de um guia de fontes - , mas pretendemos abrir o leque de pesquisas que o pode suscitar ou auxiliar em história, letras, sociologia e áreas afins.

O Arquivo Histórico começou a ser formado na década de 1940, desde a inauguração do Museu Imperial, refletindo, em seu conteúdo e organização, os objetivos e a política que levaram à criação deste museu, no Estado Novo.

A política de recolhimento das fontes e a própria organização do acervo estão intimamente ligadas à historiografia produzida na época, como também às linhas de pesquisa dos historiadores especializados no Império, que utilizaram fontes primárias do Arquivo Histórico do Museu Imperial, como é o caso de Hélio Viana, Heitor Lyra, Lídia Besouchet, Pedro Calmon, Magalhães Júnior, entre outros.

Os instrumentos de pesquisa existentes são os inventários e os índices onomásticos. Para pesquisar sobre determinado assunto, é necessário a leitura de todos os verbetes do período em questão, pois a organização segue uma ordem cronológica.

Um instrumento de pesquisa organizado em $1988^{1}$ contém a relação de todos os documentos do Arquivo Histórico referentes a assuntos, em ordem cronológica. Outro instrumento de pesquisa de grande valia são os levantamentos documentais elaborados de 
${ }^{2}$ Arquivo: conjunto de documentos que, independente da natureza ou suporte, são reunidos por acumulação no decurso das atividades de pessoas físicas ou jurídicas públicas ou privadas. Coleção: reunião artificial de documentos que, sem manter relação orgânica entre si, apresentam alguma característica comum. Ana Maria de Almeida Camargo e Heloísa Liberalli Belloto, Dicionário de Terminologia Arquivística, São Paulo, Associação dos Arquivistas Brasileiros, Núcleo Regional de São Paulo/Secretaria de Estado de Cultura, 1996. acordo com a solicitação de pesquisadores ou pela própria demanda de exposições do museu.

O acervo do Arquivo Histórico é constituído de 45 arquivos e coleções particulares. ${ }^{2}$ Apesar de encontrarmos documentos oficiais, são majoritariamente de caráter privado. Grande parte da documentação é composta de correspondências, mas se encontram também diários, anotações, desenhos, fotografias, mapas etc.

A organização do arquivo parece ter sido feita para suprir a demanda da historiografia das décadas de 1950 e 1960. Naquele período, o mais importante nos arquivos eram seus titulares: personagens que compunham a elite sócio-econômica e que poderiam, render biografias.

Essa demanda ocasionou uma forma de busca, através do índice onomástico, que procurou incluir todos os personagens citados nas correspondências. Os assuntos a que se reportava a documentação não foram contemplados, pois tal demanda tornou-se preponderante com a historiografia mais atual. O índice onomástico é constituído de fichas que remetem à localização física do documento. O processo de informatização já abrange grande parte do acervo, prevendo-se a conclusão de toda a parte inventariada no final de 1997. Como todos os inventários foram feitos em ordem cronológica, outra possibilidade é efetuar a busca por período.

Os arquivos e coleções que podem ser consultados pelo inventário e/ou índice onomástico são:
Coleção Júlio Koeler

Coleção Marques dos Santos

Coleção Martins Pinheiro

Coleção Maximiliano de Laet

Coleção Mota Maia

Arquivo Pedro Orleans e Bragança

Coleção Salgado Zenha

Coleção Silva Costa

Coleção Silva Teles

Coleção Souza Lima

Coleção Sinimbu

Coleção Smith de Vasconcelos

Coleção Soares Pinto

Coleção Vieira de Carvalho

Coleção Transferência Arquivo Nacional 
Os arquivos e coleções relacionados a seguir, igualmente relevantes, encontram-se em tratamento técnico, mas podem ser consultados com algumas limitações.

\section{NOME DO ARQUIVO}

Coleção Adir Guimarães

Coleção Américo Lacombe

Coleção Aquisição do Museu Imperial

Arquivo da Secretaria de

Obras Públicas do Rio de Janeiro

Coleção Doação Museu Imperial

Coleção Duarte Silveira

Coleção João Alfredo

Coleção Kenneth Light

Arquivo Leitão da Cunha

Arquivo Paulo Barbosa

Arquivo Pedro Paranaguá

Coleção Permuta Arquivo Nacional

Coleção Permuta Museu Imperial

Coleção Transferência Museu Imperial

Coleção Vera Bretz

Arquivo Zacarias Góis Vasconcelos

\section{ORGANIZAÇÃO}

Índice em fase de elaboração Verbetes prontos

Identificado

Índice em fase de revisão

Identificado

Índice em fase de elaboração

Identificado

Identificado

Identificado

Publicado 3

Identificado

Sem índice onomástico

Verbetes em fase de elaboração

Inventário elaborado pelo

Arquivo Nacional ${ }^{4}$

Identificado

Identificado

Inventário pronto

Índice em fase de revisão

Inventário pronto

Índice em fase de revisão
3 Encontra-se em fase de revisão para elaboração de inventário analítico. 4

O inventário deverá passar por revisão para se adequar ao modelo de outros inventários.
Dentre os 45 arquivos existentes, ressaltamos o Pedro Orleans e Bragança (POB). Doado ao Museu Imperial, em 1948, por d. Pedro Gastão de Orleans e Bragança, este arquivo pertence ao mesmo fundo do Arquivo Grão-Pará, que se encontra hoje no Palácio Grão-Pará em Petrópolis, sendo possível o acesso através de solicitação à família por telefone ou carta

A parte dessa documentação que se acha no Museu Imperial abrange o período entre 1249 e o começo do século XX, totalizando. 
cerca de 65 mil documentos. Os assuntos são os mais variados, desde os de caráter íntimo e reservado da família a documentos versando sobre episódios relevantes da história do Brasil, de Portugal e da América espanhola que, por razões variadas, foram sendo guardados pela família durante séculos.

Vamos enumerar algumas das mais importantes séries do Arquivo POB, sob a guarda do Museu Imperial:

- Documentação referente ao período de d. João VI e d. Carlota Joaquina, onde se encontram registros referentes à vinda da corte e à Questão do Prata, à negociação entre Carlota Joaquina e a Espanha, e aos interesses da Inglaterra.

- Os estudos de Pedro II sobre astronomia, matemática, física ciências naturais, história e sobre vários idiomas, entre eles sânscrito, hebraico e arábe.

- As correspondências de Pedro II com intelectuais do Brasil e do mundo, como Pasteur, Charcot, Victor Hugo, Graham Bell, Agassiz, Longfellow, Alexandre Herculano, J. Reinhart, Henri Gorceix, Von Martius, Gobineau, Conty, Daubrée, Glaziou, Gorceix, Bois Reymond, Quatrefages, entre outros.

- Diário de Pedro II, que se estende de 1840 a 1891, totalizando cerca de 4.800 páginas de cadernos de diversos tamanhos, ou cerca de 2.500 laudas digitadas. Apesar de encontrarmos lacunas nestes 51 anos, o diário é uma fonte bastante importante e está todo transcrito. Atualmente encontra-se em fase de digitação e digitalização, para a confecção de um CD-ROM.

O diário engloba desde assuntos íntimos, como sentimentos não revelados em nenhum outro documento, até os mais gerais, como pensamentos referentes à política dos partidos ou mesmo rascunhos de 'Falas do trono'. Parte são anotações feitas durante as várias viagens que Pedro II fez pelo Brasil e pelo mundo, onde relata minuciosamente o seu dia-a-dia e as suas impressões, desenha o que vê de interessante, anota palavras de vocabulário indígena, registra observações sobre a vida dos interioranos, sua moradia, seus hábitos alimentares etc.; contém inclusive observações detalhadas sobre as novas descobertas e invenções de diversos países exibidas na exposição de Filadélfia em 1876 e impressões de seus encontros com intelectuais que conheceu na Europa.

Nas viagens ao Egito, fez diversas anotações sobre a história daquela civilização. Como alguns trechos de outros diários, oimperador redigiu este todo em francês, provavelmente com a intenção de publicá-lo como trabalho científico. A egiptologia no século XIX fascinava muitos intelectuais, e o imperador era um estudioso do assunto. 


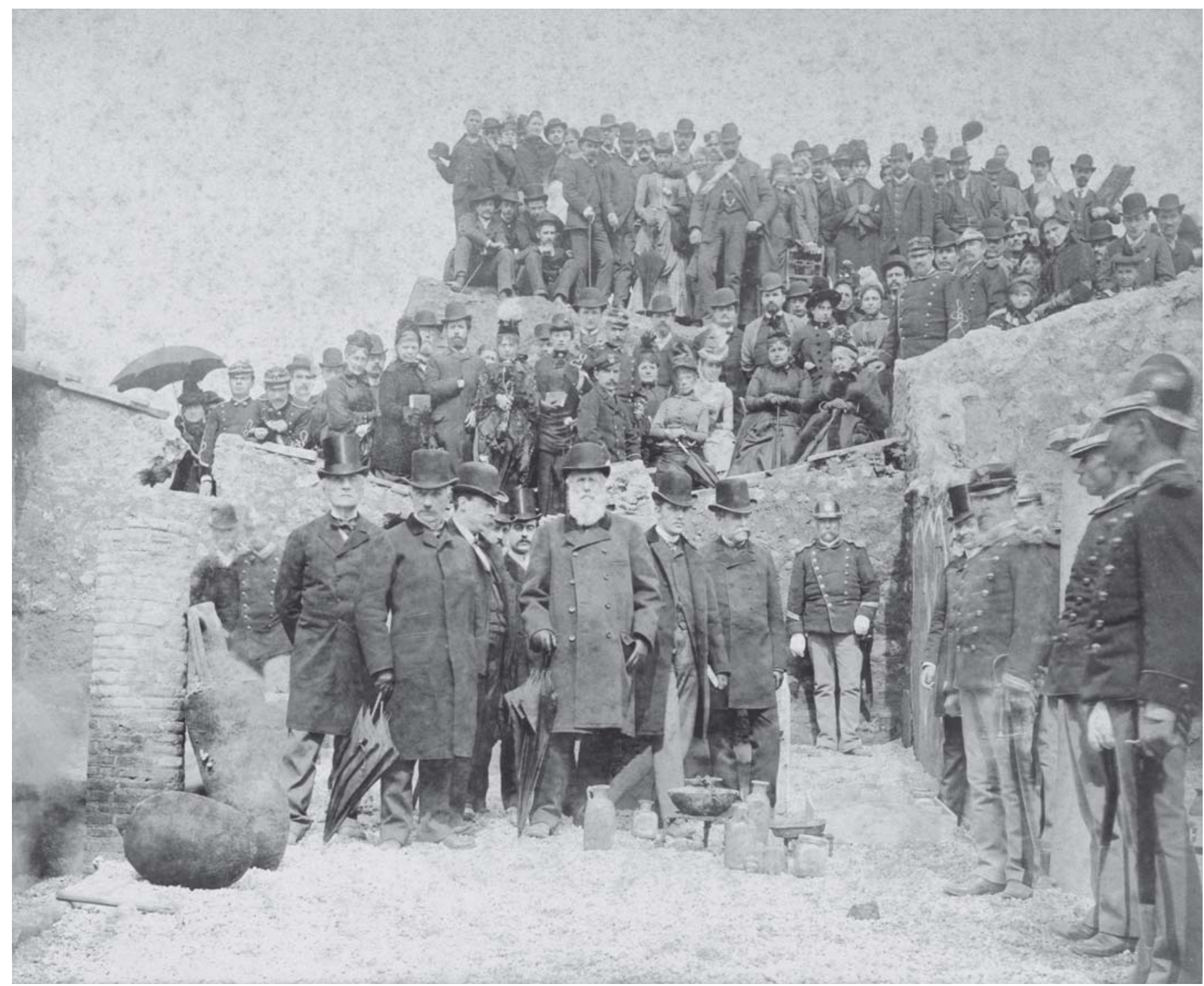

Imperador e comitiva em Pompéia, cercados de objetos recolhidos. Ele trouxe para o Brasil algo em torno de oitocentos souvenires, como talheres, vasos.

Outros volumes do diário referem-se mais a seu cotidiano, relatando de forma íntima suas preocupações com as questões políticas que agitavam o país, o ensino, a saúde e com o andamento dos estudos a que se dedicava no momento.

O aspecto mais importante dessa documentação é ter sido escrita no calor dos acontecimentos, refletindo, portanto, com menos mediações, o que realmente acontecia, diferentemente da autobiografia, que é um processo de rememoração mais suscetível à censura e à criação de imagens muitas vezes distorcidas ou mesmo idealizadas. 
${ }^{5}$ Alberto Rangel, Inventário dos documentos da Casa Imperial do Brasil, existentes no Castelo d'Eu, Rio de Janeiro, Ministério da Educação e Saúde/Biblioteca Nacional, 2 vols. (Separata do vol. LIV dos Anais da Biblioteca Nacional), 1939.

\footnotetext{
${ }^{6}$ Segundo Magalhães Júnior (D. Pedro II e a condessa de Barral, Rio de Janeiro, Civilização Brasileira, 1956, p. 56), este teria sido $\mathrm{O}$ combinado entre os dois, e apenas o imperador cumpriu a sua parte.
}

A primeira organização do Arquivo $\mathrm{POB}$ foi feita por Alberto Rangel, a pedido da família imperial, ainda no Castelo d'Eu na França. O inventário ${ }^{5}$ foi publicado em 1939, em dois volumes, pela Biblioteca Nacional, e indica de forma sumária os dados elementares para a identificação dos documentos em ordem cronológica.

A partir deste inventário, dois outros instrumentos de pesquisa foram elaborados pelo Museu Imperial: um índice alfabético das entradas consignadas por Rangel, e um inventário analítico da documentação de 1249 a 1831, com visão completa do conteúdo do acervo, apesar da falta de indexação por assunto.

Outro arquivo que elucida questões políticas do Segundo Reinado é o da condessa de Barral, onde se encontram as correspondências trocadas por ela com Pedro II. As respostas da Barral a Pedro II são em número muito menor, já que grande parte delas foi destruída pelo imperador. ${ }^{6}$ Mas a principal importância dessa correspondência reside no fato de deixar claro a influência exercida pela condessa sobre Pedro II. Durante 18 anos, estas cartas chegaram a ser quase diárias, complementando algumas lacunas da série diário do imperador Pedro II mencionada anteriormente. Nestas correspondências, podemos encontrar comentários acerca de questões fundamentais da vida política e econômica do Brasil, pedidos de conselhos etc.

$\mathrm{O}$ arquivo do marquês de Paranaguá é bastante diversificado e de grande importância para o estudo da organização política e administrativa na corte e nas províncias durante a segunda metade do século XIX, devido aos vários cargos políticos ocupados pelo titular (deputado, senador, ministro de várias pastas, presidente do Conselho) e à preocupação do mesmo em acumular e organizar o seu acervo. Trata-se de um arquivo com cerca de quatro mil documentos. Nas correspondências recebidas dos diversos presidentes de províncias percebe-se, de forma diferente dos relatórios oficiais, as preocupações, por exemplo, com a saúde, principalmente a febre amarela, cólera e varíola. Pode-se verificar como eram os critérios para o preenchimento de cargos públicos no período do Império. Iguais possibilidades oferece o arquivo de Zacarias Góis Vasconcelos, devido às várias pastas ocupadas pelo titular. Este acervo trata das questões políticas mais importantes ocorridas entre 1845 e 1877, ano de seu falecimento.

No arquivo do barão de Mamoré (Ambrósio Leitão da Cunha), encontramos documentos sobre a construção da Estrada de Ferro Madeira - Mamoré e sobre a decisiva atuação do titular no campo da saúde pública quando ministro do Império, em 1885, pela criação do chamado "cordão sanitário", que preservou o Brasil da epidemia de cólera que arrasava então o Uruguai. O barão de Mamoré ocupou vários cargos políticos, foi deputado diversas vezes, senador, presidente de quatro províncias e, finalmente, ministro do Império. O arquivo foi 
doado em 1953 e teve seu inventário publicado em 1972. Está em estudo o projeto de se elaborar um instrumento de pesquisa analítico com o objetivo de possibilitar maior conhecimento do acervo.

Os arquivos iconográfico e fotográfico — tratados separadamente - são compostos, em grande parte, de material desmembrado dos arquivos já descritos. Seu conteúdo é bastante variado: encontramse imagens de grande valor histórico, como aquelas produzidas pelos fotógrafos Nadar e Klumb, outras que documentam o imperador Pedro II com sua família ou a construção da Estrada de Ferro Madeira - Mamoré. A série de fotografias sobre Petrópolis é numerosa e bastante consultada. Na iconografia destacam-se ainda as litografias originais de Debret, Rugendas e de viajantes, desenhos do imperador Pedro II e de outros membros da família imperial.

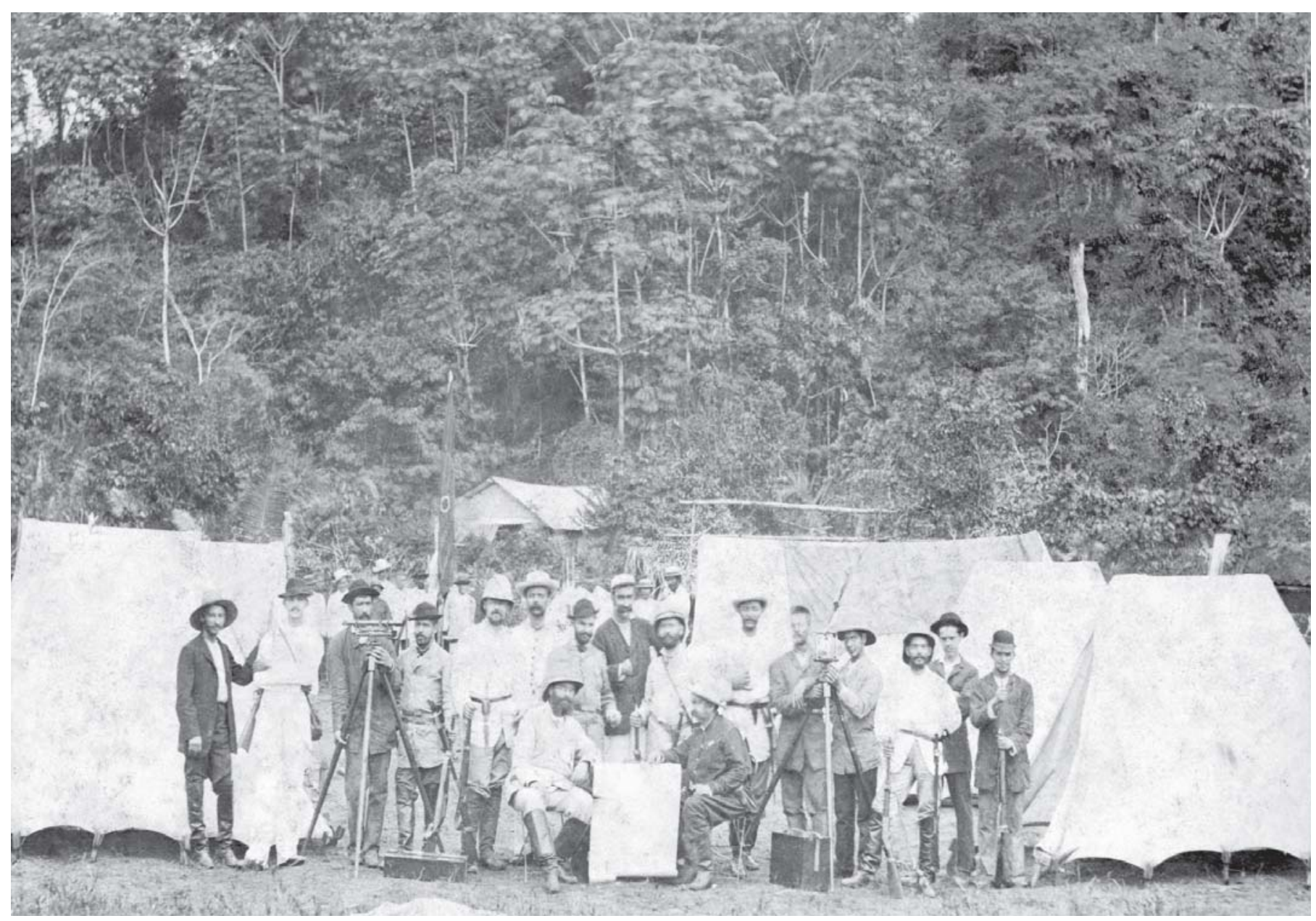

Primeiro acampamento da Comissão de Estradas da Estrada de Ferro Madeira - Mamoré, em Santo Antônio. Abril de 1885, Amazonas. 


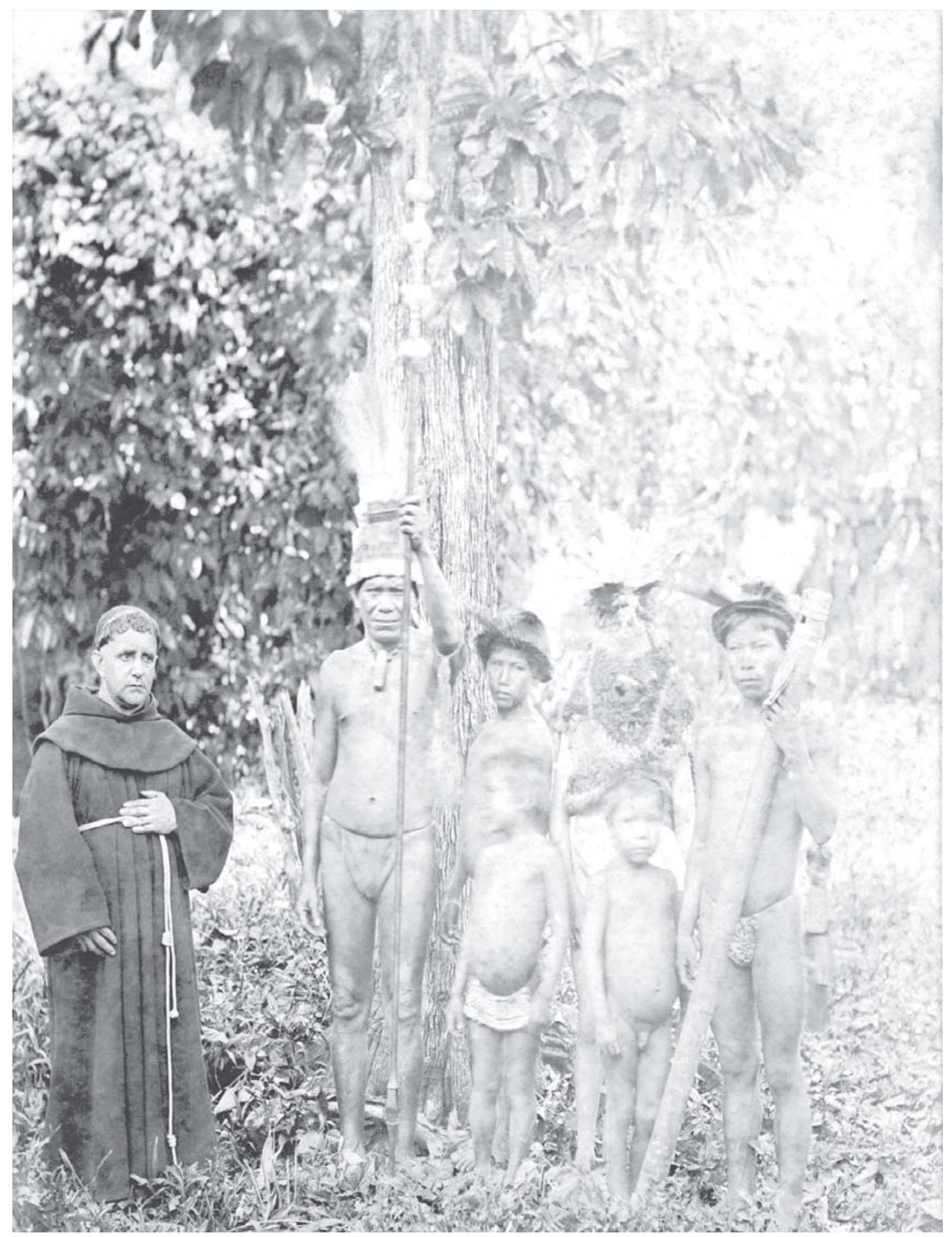

Touchana e família de índios tarianos, habitantes das margens do rio Waupes, no Amazonas. 
Vê-se, assim, que são consideráveis as potencialidades do acervo. Ainda que nenhum de seus arquivos esteja ligado diretamente à história das ciências e/ou da saúde, em várias séries encontram-se fontes que auxiliam a exploração desses campos do conhecimento.

\section{Begonha Bediaga}

Bacharel em história, pesquisadora da Casa de Oswaldo Cruz cedida ao Museu Imperial. Rua das Dálias, 67 - Vale da União 25725-040 Petrópolis - RJ Brasil E-mail: bediaga@npoint.com.br

\section{Serviço}

A consulta ao Arquivo Histórico pode ser feita de segunda a sexta-feira, das 13:30h às 17:30h. Visitas na parte da manhã devem ser marcadas com antecedência, por telefone. O levantamento documental é realizado para os pesquisadores que moram fora do estado do Rio de Janeiro, e deve ser solicitado por carta, telefone ou e-mail, em nome da equipe do Arquivo Histórico, especificando-se $\mathrm{o}$ assunto. $O$ museu fornece fotocópia de documentos (em bom estado de conservação), ao custo de $R \$ 0,20$ cada cópia. Caso haja necessidade de fotografar algum documento iconográfico ou escrito, é necessário mandar carta ou fax solicitando autorização à direção do Museu Imperial, esclarecendo-se o objetivo da reprodução. O pesquisador deve

trazer o equipamento.

Endereço: rua da Imperatriz, 220

25610-320 Petropolis - RJ Brasil

Tel.: (024) 237-8000

$\operatorname{Fax}(024)$ 237-8540.

E-mail: musimp@compuland.com.br. 